\title{
Paediatric nurses: A boon to our child care services
}

\author{
Sri Lanka Journal of Child Health, 2002; 31: 73-4
}

(Key words: paediatric nurses)

It is an undisputed fact that nurses involved in the care of the health and welfare of children provide a necessary, valuable and yeomen service. They are the ministering angels who are there with the children, through the good times and bad, during illness and health and for that matter, even for better or for worse. No community, anywhere in the world, could do without them in the hallowed traditions of paediatric care. In our own land, they are a set of health care workers who, silently, efficiently and without that much of a fuss, make sure that all is well with the sick children in our hospitals and also look after the well children in the community.

Paediatric nursing is a highly specialised art and an accomplished science. This particular segment of the profession needs special care and training. Many countries, especially in the developed world have specially designed training programmes for those going into a career of nursing children. Some offer career advancement programmes specifically targeted to those nurses involved in the care of children. In some parts of the world, there is even sub-specialisation of nursing into areas like paediatric intensive care, child psychiatry, renal diseases, community work etc. In these countries, the importance of the paediatric nursing profession as an essential and integral part of child care is recognised and suitable action taken to further the cause of these valuable health care personnel. There are comprehensive advanced courses ${ }^{1}$, scholarships $^{2}$, specialised courses $^{3}$ and even dedicated journals ${ }^{4}$ for paediatric nurses in many countries.

Sri Lankan public service boasts of nine Nurses Training Schools scattered throughout the island. The new recruits are enlisted on the GCE "A' Level results together with a pass in English at the GCE '0' Level examination. It is a 3 year course, out of which only around 175 hours of teaching is dedicated to a combined slot of maternity and child care. This is part of routine training and the hours include a variable combination of theory and practical work. Once they graduate, there is no special system to appoint them into the paediatric nursing segment and it seems that the appointments are not made on any standardised system. Regrettably, the relatively small period of paediatric training during the student days does not prepare them adequately to the responsibilities of paediatric nursing, at least initially. In addition, there are some private institutions that organise nurses training programmes through the private hospitals. These too do not prepare them for a career in specialised paediatric nursing.

It is not uncommon in this country to see a few nurses, especially at night when only just two or three of them are available, look after and care for all the sick children in a busy paediatric unit. Under trying circumstances they perform extremely well and it is a real credit to their profession that the instances of things going wrong in our wards are very few and far between. When the going gets really tough, they are well known to rise to the occasion. To compound the situation further, they are really very lowly paid and some of them are forced to do extra duties to earn a few rupees more.

Our nurses have some programmes of in-service training during the many years of service following graduation but these are not specifically targeted to paediatric nursing. After several years of service they are allowed to sit for an examination for selection as Nursing Sisters. Then they go through an 18 month period of training to become a sister. There is no special programme for training of Paediatric Sisters. Very few opportunities are available for postgraduate career advancement for them. Recently, the Open University has started a B.Sc. course for nurses and the Sri Jayawardenapura University is just starting a M.Sc. course. However, none of these are of a specialised nature for a career in paediatric nursing.

Ironically, our nurses and the priceless services they perform, are taken for granted. Authorities concerned have very rarely addressed their grievances and looked at ways and means of making them happy in their work. Many a time, they have had to resort to unpleasant courses of action like trade union sponsored work stoppages even to establish an initial dialogue on a pressing problem. The powers that be tend to treat them like poor cousins.

It is time that the extremely valuable services provided by those nurses who look after children be recognised as essential, specialised and on par with other specialised child care services. They should be accepted as yet another set of expert workers who perform an important and 
indispensable function in the care of children. They should be provided with avenues of career advancement and perhaps it is time the authorities started thinking in terms of a Post- graduate Institute of Nursing, akin to the now firmly established Postgraduate Institute of Medicine.

\section{References}

1. http://www.nursingstandard.co.uk/courses/cour ses.htm Accessed 01-09-2002.
2. http://www.abon.ora.uk Accessed 01-09-2002.

3. http://www.acenl.org.au Accessed 02-092002.

4. http://pedwebwww.uia.ac.be/oedweb/iournoed. htm Accessed 02-09-2002

B J C Perera

Joint Editor 